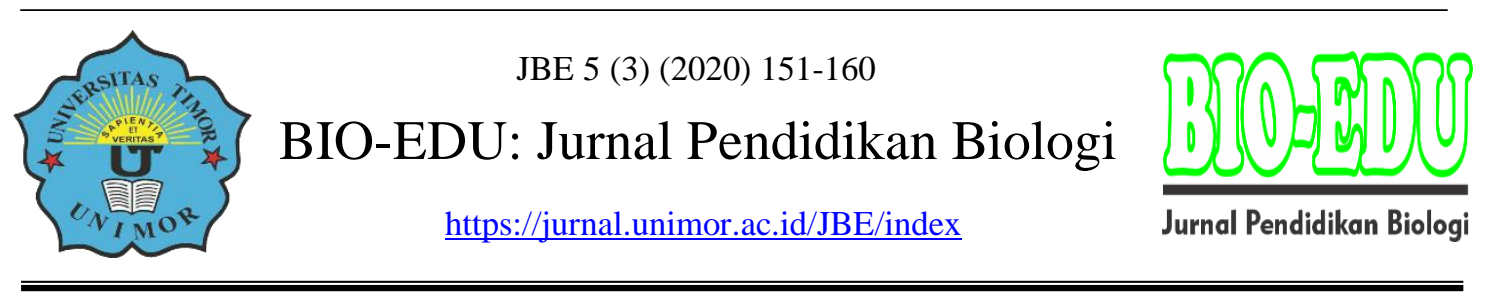

\title{
Identifikasi Jamur Makroskopis di Kawasan Hutan Lindung Kaleakan Kecamatan Nanggala Toraja Utara
}

\author{
Arwin Arif ${ }^{1}$, Maisya Zahra Al-Banna ${ }^{2}$ \\ Program Studi Pendidikan Biologi STKIP-PI Makassar, Jl. Inspeksi Kanal Citraland \\ No.10, Kec Rappocini, Kota Makassar, Sulawesi Selatan \\ Email : arwinarif29@gmail.com
}

DOI: https://DOI 10.32938/jbe. v5i3.731

\begin{abstract}
Abstrak
Identifikasi jamur makroskopis di kawasan hutan lindung Kaleakan.Tujuan dalam penelitian ini adalah untuk mengetahui berbagai jenis Jamur Makroskopis yang terdapat di kawasan Hutan Lindung Kaleakan Kecamatan Nanggala Toraja Utara. Teknik pengumpulan sampel dilakukan dengan metode jelajah dengan membuat ploat menggunakan tali dengan ukuran 25 x 25 Meter .Sedangkan teknik analisis data dilakukan secara deskriftif kualitatif. Dalam penelitian ini menunjukkan terdapat 33 spesies jenis jamur makroskopis yang ditemukan di lokasi penelitian, dimana seluruhnya berasal dari divisi Basidiomycota yang terdiri atas 3 kelas, 8 ordo, 22 famili, 28 genus. Ordo yang paling banyak ditemukan adalah ordo Polyporales dan famili yang paling banyak ditemukan adalah kelompok jamur dari family Poliporaceae. Berdasarkan keadaan tutupan lahan pada daerah hutan gundul dengan intensitas cahaya tinggi ditemukan 3 jenis jamur, yaitu Ganoderma sp, Postiastipticus, Nigroporusvinosus. Berdasarkan substratnya, pada kayu lapuk ditemukan 19 jenis jamur (53\%), serasah/tanah 13 jenis jamur (36\%) dan pada kayu hidup 4 jenis jamur(11\%). Sehingga kebanyakan jamur yang hidup di kawasan hutan lindung Kaleakan Kecamatan Nanggala Toraja Utara adalah jenis jamur kayu (wood fungy) yang umumnya berperan sebagai Sabrofit, pelakuk kayu/dekomposer.
\end{abstract}

Kata Kunci: Identifikasi, Jamur Makroskopis, Kawasan Hutan Lindung Kaleakan, Toraja Utara.

\begin{abstract}
Identification of macroscopic fungi inKaleakan protected forest area. This research aims to find out of fungi Macroscopic Fungi anything contained in a protected Forest area of Kaleakan sub-district of TorajaNanggala North? ". Sample collection technique is done by the method of cruising whit ploat size $25 \times 25$ meters While the techniques of data analysis done on qualitative deskriftif. In this research showed there are 33 types of macroscopic fungi species were found at the site of the study, which is entirely derived from the Division Basidiomycota consisting of 3 classes, 822 order, family, genus 28 . The order of the most widely found is the order Polyporales and family is the most widely found was a group of mushroom of the family Poliporaceae. Based on the State of the land cover in forest areas denuded by high light intensity found 3 mushroom types, namely Ganoderma sp, Postiastipticus, Nigroporusvinosus. According to the substrate, in the wood rotted found 19 kinds of mushrooms (53\%), litter/soil 13 types of mushrooms (36\%) and in the wood of life 4 types of mushrooms (11\%). So most fungi that live in the protected forest area of Kaleakan Subdistrict NanggalaToraja Utara is a type of mushroom wood (wood fungy) generally acts as having Sabrofit, decomposer.
\end{abstract}

Keywords: Identification, Macroscopic Fungi, Kaleakan Protected Forest Area, Toraja Utara. 


\section{PENDAHULUAN}

Indonesia merupakan salah-satu negara yang memiliki tingkat keanekaragaman hayati yang sangat tinggi.Indonesia adalah megabiodiversitas, wilayah Indonesia hanya $1,3 \%$ dari seluruh luas permukaan bumi, tetapi menyimpan $17 \%$ dari seluruh jumlah spesies di dunia (Subardidkk, 2009). Keanekaragaman flora Indonesia tercermin pada kekayaan hutan tropiknya, baik yang terdapat di dataran rendah maupun di dataran tinggi yang menutupi 63\% luas daratan Indonesia. Di hutan-hutan inilah sebagian besar dijumpai tumbuhan yang merambat, berbentuk perdu, dan pohon dengan berbagai ukuran, selain itu juga terdapat organisme lain seperti ganggang, lumut dan jamur (Iswanto, 2009). Atas dasar itulah maka perlu dilakukan kegiatan penelitian serta pengumpulan data terhadap kekayaan sumber daya alam hayati khususnya di Indonesia guna memberikan gambaran atau potret mengenai kekayaan serta keanekaragaman sumber daya alam hayati yang terdapat di berbagai wilayah di Indonesia. Salah-satu bagian dari kekayaan hayati adalah jamur. Jamur umumnya menempati berbagai tipe habitat yaitu tanah, kayu, serasah, kotoran hewan dan sebagainya.Tipe ekosistem yang dapat ditumbuhi jamur adalah hutan, karena hutan memiliki tingkat kelembapan yang tinggi sehingga jamur mudah beradaptasi selain itu fungsi ekologis jamur dalam ekosistem hutan yaitu sebagai dekomposer.(Annissa dkk, 2017).

Jamur memiliki potensi untuk dimanfaatkan selain fungsi alaminya sebagai dokomposer dalam ekosistem. Sekitar 70.000 spesies jamur telah dapat diidentifikasi dari jumlah spesies di alam yang diperkirakan 1,5 Juta (Hawnksworthet al, 1995 dalam Handayanto dan Hairiah, 2009). Sejumlah 200.000 spesies dari 1,5 juta spesies jamur di seluruh dunia diperkirakan ada di Indonesia ( Rifai, 1995 dalam Gandjar, 2018). Hingga saat ini terdapat kurang lebih 35 spesies jamur yang telah dibudidayakan secara komersial di dunia dan kurang lebih 20 jenis jamur telah dibudidayakan pada skala industri.Jamur tersebut merupakan jamur yang bisa dikonsumsi (Edible mushrooms) dan jamur yang tidak dapat dikonsumsi namun memiliki khasiat sebagai obat (medical mushrooms) (Liswidyawati, 2012).

Seperti telah dijelaskan di atas, bahwa hutan merupakan habitat bagi jamur. Di

Provinsi Sulawesi Selatan banyak terdapat kawasan hutan yang merupakan habitat alami bagi jamur. KabupatenToraja Utara merupakan salah-satu bagian dari provinsi Sulawesi Selatan. Letaknya yang berada di daerah dataran tinggi dengan iklim sejuk dan lembab, serta memiliki banyak kawasan hutan lindung, merupakan tempat yang tepat untuk melakukan penelitian terhadap jenis jamur. Salah-satu bagian dari kawasan hutan lindung di Toraja Utara adalah kawasan hutan lindung Kaleakan yang berada di Kecamatan Nanggala dan letaknya tidak jauh dari perbatasan antara kabupaten Toraja Utara dan Kabupaten Luwu. Kawasan hutan ini dipilih karena kealamiannya masih sangat terjaga dan aksesnya yang cukup mudah dijangkau, karena kawasan hutan yang dilalui oleh jalan trans Sulawesi.

Kawasan hutan lindung Kaleakan Kecamatan Nanggala, merupakan kawasan hutan yang masih sangat jarang di eksplorasi, hal itu karena statusnya sebagai hutan lindung membuat segala aktifitas eksplorasi dan pemanfaatan hutan menjadi dibatasi dan hanya memilki fungsi tunggal sebagai hutan lindung yang memilki peran untuk menjaga keseimbangan alam, seperti yang dijelaskan dalam UU RI No 41 Tahun 1999 Tentang Kehutanan, bahwa kawasan hutan lindung adalah kawasan hutan yang mempunyai fungsi pokok sebagai perlindungan sistem penyangga kehidupan untuk mengatur tata air, mencegah banjir, mengendalikan erosi, mencegah intrusi air laut, dan memelihara kesuburan tanah. 
Kawasan hutan lindung Kaleakan Kecamatan Nanggala telah dijadikan kawasan hutan lindung sejak zaman Hindia Belanda melalui SK ZelfBesteuur No. 13 dan No. 14 Tahun 1932 (Hadijah, 2009). Secara geografis kawasan ini berada diantara 11957'26" sampai $120^{\circ} 05^{\prime} 00^{\prime \prime}$ Bujur Timur dan $02^{\circ} 56^{\prime} 08^{\prime \prime}$ sampai $03^{\circ} 04^{\prime 2} 5^{\prime \prime}$ Lintang Selatan dengan ketinggian berkisar 800 hingga 1639 meter dari permukaan laut (Walda, 2002 dalam Hadijah, 2009). Sementara dalam hal iklim,secara umum termasuk beriklim tropis dengan suhu berkisar antara $14^{\circ}-26^{\circ}$ celcius dengan tingkat kelembaban udara antara $82 \%$ - $86 \%$ sehingga tergololong iklim tropis basah (Anonim, 2016). Luas keseluruhan kawasan berdasarkan SK.2414/MENLHK/PTKL/KUH/PLA.2/4/2017 tentang peta perkembangan pengukuhan kawasan hutan provinsi Sulawesi Selatan sampai tahun 2016 luas KPHL saddang II adalah 52.445 Ha yang merupakan hasil dari perkembangan tata batas sehingga ditetapkan bahwa luas yang sebenarnya adalah $52.445 \mathrm{Ha}$, sementara itu yang termasuk ke dalam kawasan hutan lindung Nanggala memiliki luas $2.351 \mathrm{Ha}$ atau mencapai $41.01 \%$ dari luas Kecamatan Nanggala secara keseluruhan dan hanya memiliki fungsi hutan lindung dan tidak ada fungsi lain(Anonim, 2018)

Lokasi penelitian memiliki dua musim dimana musim kemarau terjadi pada bulan Juni-September dan musim hujan terjadi pada bulan Desember-Maret, walaupun faktanya pola musim di lokasi penelitian tidak konstan karena seluruh wilayah Tana Toraja maupun Toraja Utara hingga wilayah Luwu yang berbatasan langsung dengan lokasi penelitian tidak memiliki zona musim. Hal tersebut membuktikan bahwa tingkat curah hujan yang tinggi membuat kawasan ini memiliki kelembapan yang tinggi pula, sehingga menjadi habitat yang baik untuk pertumbuhan jamur, karena selain faktor nutrisi faktor lingkungan juga sangat berpengaruh terhadap pertumbuhan jamur (kelembapan, intensitas cahaya, $\mathrm{pH}$, temperatur) dan dapat menentukan jenis jamur yang dapat tumbuh dengan baik, karena walaupun umumnya jamur memiliki kisaran toleransi yang relatif sama terhadap lingkungan, namun pada nyatanya beberapa jenis jamur memilki kemampuan adaptasi yang baik dan toleransi yang cukup tinggi terhadap lingkungan.

\section{METODE}

Metode dalam penelitian ini menggunakan metode jelajah, karena dianggap lebih efektif untuk mengobservasi, mengumpulkan sampel yang sebarannya tidak rata dalam kawasan hutan yang luas. Adapun teknik penentuan titik pengambilan sampel menggunakan teknik Sampling Purposive, yang mana teknik penentuan sampel ditentukan berdasarkan berbagai pertimbangan, dalam hal ini yang menjadi pertimbangan untuk menentukan lokasi jelajah adalah akses hutan, keadaan tutupan lahan dan yang paling utama adalah faktor keamanan. Identifikasi dilakukan melalui studi pustaka dengan melakukan banding dengan penelitian sebelumnya, baik melalui buku, jurnal penelitian dan website terpercaya.

\section{HASIL DAN PEMBAHASAN}

Area penelitian atau lokasi pengambilan sampel memiliki topografi yang didominasi oleh medan berbukit serta lereng atau lembah, dengan ketinggian dari permukaan laut berada pada kisaran 1103-1350 mdpl. Pengukuran dilakukan dengan menggunakan software standar UPT KPH Saddang II yaitu GPS Essentials Versi 4.4. 


\section{a. Letak atau Titik Koordinat Pengambilan Sampel}

Titik Pengambilan sampel dipilih dengan menjadikan pos pengawasan milik UPT KPH Saddang II sebagai titik awal atau start (S 0257.248” E12003.054”. 1207 mdpl ). Kemudian 1okasi pengambilan sampel dipilih berdasarkan pertimbangan tingkat kemudahan untuk dijangkau, dimana dengan menyusuri area pinggiran hutan sampai

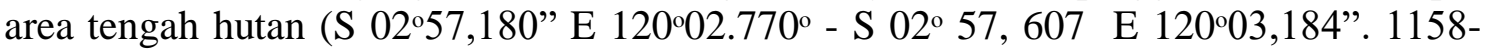
1350 mdpl) hingga kawasan hutan yang berdekatan atau berbatasan dengan hutan Masyarakat yang didominasi oleh vegetasi hutan pinus dan terdapat bekas kebakaran hutan (S 02 ${ }^{\circ} 56,860^{\prime}$ E 120 02. 224”. 1103 mdpl). Titik koordinat didapatkan denganmenggunakan software standar UPT KPH Saddang II yaitu GPS Essentials Versi 4.4. Lokasi pengambilan sampel tidaklah sama persis dengan titik koordinat melainkan pengambilan sampel dilakukan dengan menjelajahi area di sekitar koordinat baik dengan berkeliling ataupun dengan mengambil rute lurus atau mengikuti rute umum yang digunakan polisi kehutanan jika berpatroli dengan menyusuri kawasan hutan, dengan jarak tempuh $\pm 100-1000 \mathrm{~m}$, sehingga titik koordinat hanya berfungsi sebagai penanda lokasi sekitar pengambilan sampel.

\section{b. Hasil Temuan Jamur Makroskopis}

Adapun hasil temuan jamur makroskopis di kawasan hutan lindung Kaleakan akan dikelompokkan sebagai berikut :

\section{1) Sebaran Jenis Jamur Berdasarkan Kenampakan Tutupan Lahan}

Berdasarkan kenampakan tutupan lahan, secara umum lokasi penelitian merupakan hutan tertutup dan lebat, karena statusnya sebagai hutan lindung sehingga segala bentuk aktifitas pemanfaatan hutan sangat dibatasi. Hal inilah yang membuat hampir seluruh daerah kawasan memilki tutupan lahan dan kanopi yang lebat sehingga jumlah intensitas cahaya yang masuk menjadi rendah. Namun terdapat sedikit kawasan hutan yang gundul akibat kebakaran dan hanya ditumbuhi semakbelukar dan tumbuhan paku-pakuan serta masih terdapat beberapa batang pohon yang berdiri walaupun sudah tidak memiliki ranting dan mulai mengering.

Berdasarkan hal itu maka kemudian dilakukan perbandingan jenis jamur makroskopis yang tumbuh pada kawasan hutan lebat dengan kawasan hutan yang sudah gundul. Dalam penelitian ini ditemukan perbedaan jenis jamur berdasarkan kondisi tutupan lahan, Adapun perbandingan hasil yang ditemukan dapat dilihat pada tabel 1

Tabel 1. Data Sebaran Jamur Berdasarkan Tutupan Lahan

\begin{tabular}{lcc}
\hline \hline Spesies & Hutan Lebat & Hutan Gundul \\
\hline Ganoderma appaltum & $\checkmark$ & $\checkmark$ \\
Heterobasidion & $\checkmark$ & \\
annosum & $\checkmark$ & \\
Schizophyllum commune & $\checkmark$ & \\
Tremetessp & & \\
Dacryopinax & $\checkmark$ & \\
spathularia & $\checkmark$ & \\
Lentinus sajor caju & $\checkmark$ & \\
Lentinus sp & $\checkmark$ & \\
Microporus xanthoporus & $\checkmark$ & \\
Mikroporus affinis & $\checkmark$ & \\
Microporus sp & & \\
Nigroporus vinosus & &
\end{tabular}




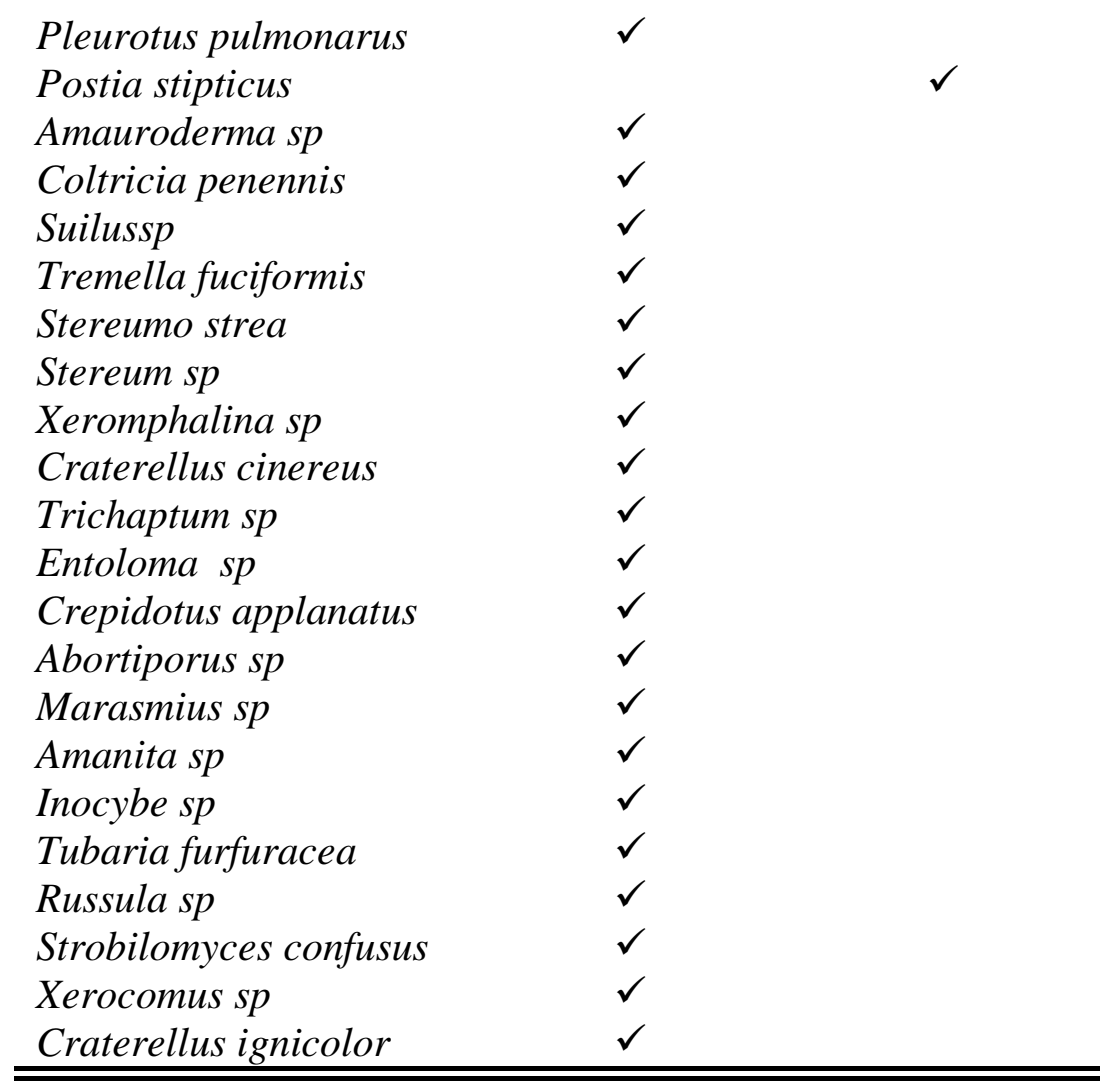

( Sumber: Data Primer ,2019)

Salah satu faktor yang mendukung pertumbuhan jamur makroskopis adalah Intensitas cahaya. Menurut Suriawiria (2006) jamur sangat peka terhadap cahaya matahari secara langsung. Tempat-tempat yang teduh sebagai pelindung merupakan tempat yang baik bagi pertumbuhan dan perkembangan jamur. Hal sama juga ditegaskan oleh Khayati (2016) dalam penelitiannya mengatakan bahwa berkurangnya pohon-pohon yang menaungi lantai hutan akibat penebangan pohon sehingga intensitas cahaya yang masuk semakin banyak, membuat tanah dan serasah-serasah daun yang tidak ternaungi menjadi kering dan tidak lembab lagi sehingga jamur tidak dapat tumbuh. Berdasarkan kenampakan tutupan lahan, peneliti mencoba membandingkan jenis jamur makroskopis yang hidup pada daerah hutan lebat dan hutan gundul bekas kebakaran yang tidak memiliki kanopi.Hasil penelitian membuktikan bahwa di daerah hutan gundul bekas kebakaran yang tidak memiliki kanopi dan tutupan lahan serta intensitas cahaya yang tinggi, terdapat tiga jenis jamur yang ditemukan yaitu Ganoderma applatum, Postiastipticus dan Nigroporusvinosus.

Berdasarkan hasil penelitian yang dilakukan, maka diperoleh 33 Spesies jamur Makroskopis yang seluruhnya termasuk dalam Divisi Basidiomycota dan terdiri dari 3 kelas, 8 ordo, 22 familidan 28 genus.Hasil ini sesuai dengan pernyataan Dwidjoseputro (1978) dalam Sri (2017) yang menerangkan bahwa, karakteristik Basidiomycota antara lain kebanyakan makroskopis sedangkan kebanyakan Ascomycota bersifat mikroskopis, hanya sebagian kecil yang bersifat makroskopis dan memiliki tubuh buah.Ordo yang paling banyak ditemukan adalah jamur yang berasal dari ordo Polyporales dimana terdapat 12 jenis jamur. Hal ini dikarenakan pada umumnya Ordo Polyporales memiliki kemampan adaptasi yang tinggi serta didukung dengan struktur tubuh buahnya yang cenderung keras dan kokoh sehingga lebih tahan terhadap perubahan iklim atau cuaca. 
Sementara itu dari ordo Polyporales, famili yang paling banyak ditemukan adalah famili dari Poliporaceae dan Ganodermataceae. Dari kedua famili ini jika diamati umumnya memiliki struktur berkayu, utamanya dari genus ganoderma karena jamur ini hampir ditemukan di seluruh lokasi pengambilan sampel yang menandakan bahwa jumlahnya cukup melimpah. Jamur ini dapat tumbuh dalam jangka waktu bertahun-tahun dan mampu mencapai diameter $25 \mathrm{~cm}$. Hal ini didukung oleh penelitian sebelumnya yang dilakukan Tambaru, dkk (2016) menyatakan bahwa karakteristik jamur family Polyporaceae dan Ganodermataceae memiliki tubuh buah berupa suatu kipas, himenifora merupakan buluh-buluh (pori) yang dilihat dari luar berupa lubang-lubang badan buah.Tubuh buahnya berumur satu tahun setiap kali membentuk lapisan-lapisan himenoforabaru (Yunida, 2014 dalam Lestari, 2018).

\section{3) Jumlah Jenis Jamur Berdasarkan Famili}

Hasil penelitian menunjukkan terdapat 33 jenis jamur yang ditemukan yang terdiri dari 22 famili. Famili yang terbanyak adalah Poliporaceae yang terdiri dari 8 jenis, hal itu menunjukkan bahwa family Poliporaceae merupakan famili yang yang jumlah jenisnya paling mendominasi di lokasi penelitian. Jamur dari family poliporaceae yang ditemukan umumnya hidup pada substrat kayu, baik itu kayu yang telah lapuk/mati maupun yang masih hidup, sehingga tergolong sebagai jamur kayu (wood fungy)

Berdasarkan hasil pengamatan kelompok jamur ini memiliki struktur tubuh buah yang cenderung keras dan tidak lunak kecuali Lentinus sajorcaju dan lentinus sp. Faktor substrat kemungkinan menjadi salah pendukung sehingga jumlah jenis dari family Poiporaceae lebih mendominasi, hal itu karena pada lokasi penelitian merupakan hutan tertutup karena statusnya sebagai hutan lindung sehingga banyak ditemukan kayu yang sudah tua dan mati secara alami dan dibiarkan begitu saja karena memang sesuai aturan bahwa dalam kawasan hutan lindung tidak boleh mengambil kayu walupun telah mati. Disinilah peran jamur sebagai pengurai alami. Banyaknya substrat yang sesuai membuat banyak juga jenis jamur kayu yang tumbuh.

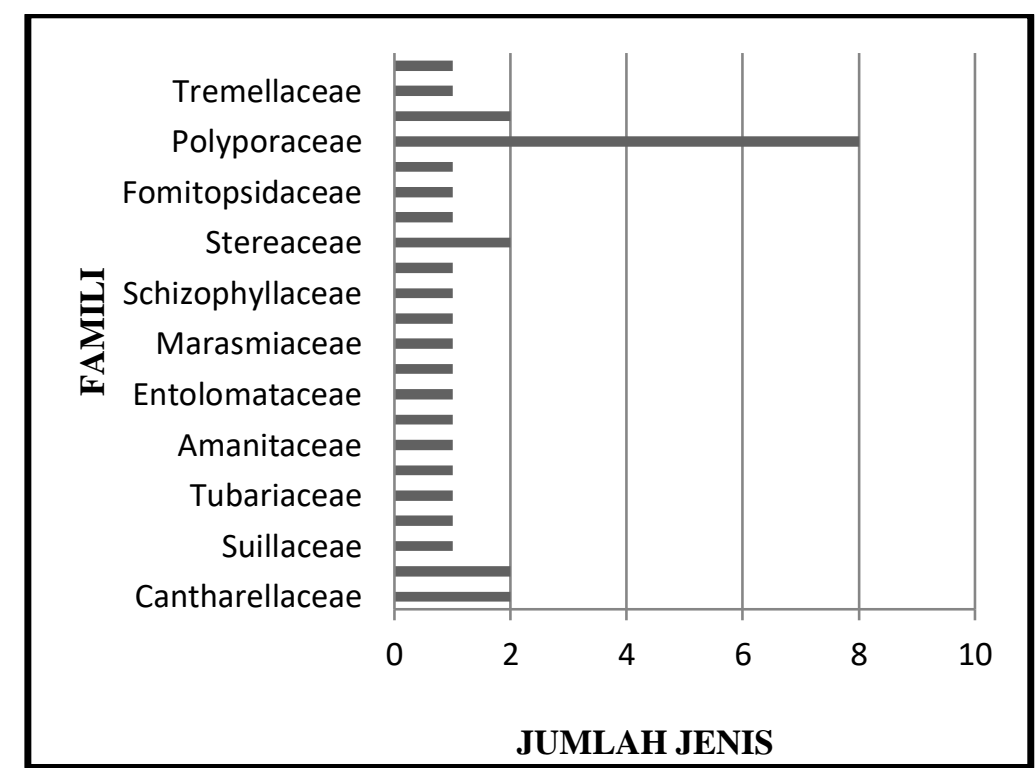

Gambar1. Grafik Jumlah Jenis Jamur Makroskopis Berdasarkan Famili 


\section{4) Pengelompokan Jamur Berdasarkan Substrat.}

Berdasarkan substrat tempat tumbuh jamur yang ditemukan dibedakan atas tiga jenis substrat yaitu Tanah/serasah, kayu (hidup), kayu lapuk. Dari hasil penelitian menunjukkan jamur yang hidup pada kayu lapuk sangat mendominasi, Adapun hasil pengelompokan berdasarkan substrat dapat kita lihat pada tabel 2.

Tabel 2.Data Pengelompokan Jamur Berdasarkan Substrat

\begin{tabular}{|c|c|c|c|}
\hline \multirow[t]{2}{*}{ SPESIES } & \multicolumn{3}{|c|}{ SUBSTRAT } \\
\hline & Kayu Lapuk & Serasah/Tanah & Kayu \\
\hline Ganoderma appalatum & $\checkmark$ & & $\checkmark$ \\
\hline Heterobasidion annosum & $\checkmark$ & & \\
\hline Schizophyllum commune & $\checkmark$ & & \\
\hline Tremetessp & $\checkmark$ & & \\
\hline Dacryopinax spathularia & $\checkmark$ & & \\
\hline Lentinus sajor caju & $\checkmark$ & & \\
\hline Lentinus sp & $\checkmark$ & & \\
\hline Microporus xanthoporus & $\checkmark$ & & \\
\hline Mikroporus affinis & $\checkmark$ & & \\
\hline Microporus sp & $\checkmark$ & & \\
\hline Nigroporus vinosus & $\checkmark$ & & \\
\hline Pleurotus pulmonarus & $\checkmark$ & & \\
\hline Postia stipticus & $\checkmark$ & & \\
\hline Amauroderma sp & & $\checkmark$ & \\
\hline Coltricia penennis & & $\checkmark$ & \\
\hline Suilussp & & $\checkmark$ & \\
\hline Tremella fuciformis & $\checkmark$ & & $\checkmark$ \\
\hline Stereum ostrea & $\checkmark$ & & \\
\hline Stereum $s p$ & $\checkmark$ & & \\
\hline Xeromphalina sp & $\checkmark$ & & \\
\hline Craterellus Ignicolor & & $\checkmark$ & \\
\hline Craterellus cinereus & & $\checkmark$ & \\
\hline Trichaptum sp & & & $\checkmark$ \\
\hline Entoloma sp & & $\checkmark$ & \\
\hline Crepidotus applanatus & $\checkmark$ & & \\
\hline Abortiporus sp & & $\checkmark$ & \\
\hline Marasmius sp & & $\checkmark$ & \\
\hline Amanita sp & & $\checkmark$ & \\
\hline Inocybe sp & & $\checkmark$ & \\
\hline Tubaria furfuracea & $\checkmark$ & & \\
\hline Russula sp 1 & & $\checkmark$ & \\
\hline Strobilomyces confusus & & $\checkmark$ & \\
\hline Xerocomus sp & & $\checkmark$ & $\checkmark$ \\
\hline Jumlah & 19 & 13 & 4 \\
\hline Persentase & $53 \%$ & $36 \%$ & $11 \%$ \\
\hline
\end{tabular}

Hasil penelitian yang dilakukan terdapat 3 jenis substrat sebagai tempat tumbuh jamur yaitu : Pohon/Kayu (hidup), Serasah/tanah, dan Kayu Lapuk(Mati). Pada Substrat 
kayu (hidup). Pada substrat kayu lapuk ditemukan 19 jenis jamur (53\%), pada substrat serasah/tanah ditemukan 13 jenis (36\%) dan pada substrat kayu hidup 4 jenis(11\%). Berdasarkan hal tersebut maka diperoleh data bahwa umumnya jamur yang ditemukan di lokasi penelitian adalah jamur yang tumbuh pada substrat kayu lapuk.Adapun gambaran perbandingan dapat kita lihat pada gambar 2 .

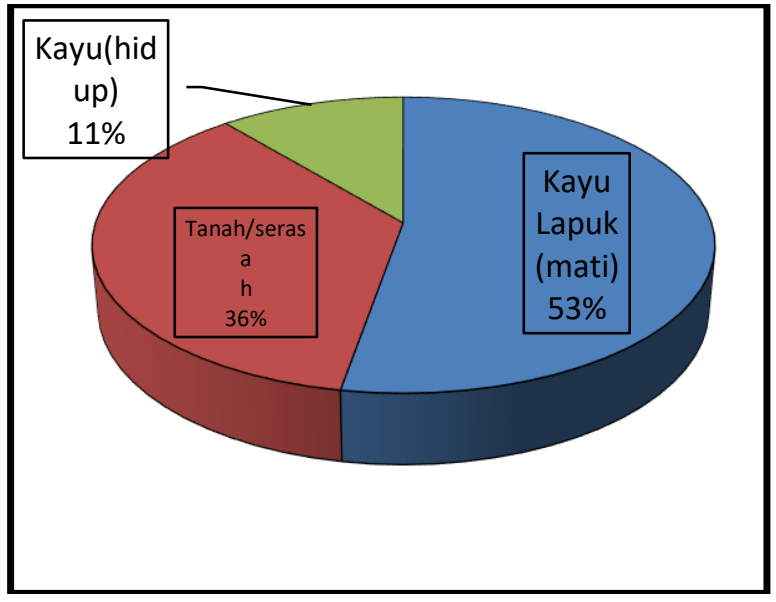

Gambar 2. Grafik Perbandingan Jumlah Spesies Berdasarkan Substrat

Dari data di atas maka sangatj jelas bahwa dari pengelompokan jamur berdasarkan substrat (kayu,tanah/serasah,kayu lapuk) hampir 50\% jamur yang ditemukan di lokasi penelitian tumbuh pada kayu lapuk. Hal ini menunjukkan maka umumnya jamur yang hidup di kawasan hutan lindung Kaleakan adalah jenis jamur pelapuk kayu. Jika ditotalkan dengan semua jamur yang hidup pada kayu baik yang masih hidup maupun sudah lapuk atau mati maka $89 \%$ dari total keseluruhan jenis jamur yang ditemukan di lokasi penelitian termasuk kelompok jamur kayu (wood fungy). Jamur jenis ini memiliki aktivitas selulotik yang sangat kuat, jamur ini mampu mendegradasi lignin dan selulosa yang merupakan komponen utama penyusun tubuh kayu(Gandjar, 2018). Sehingga umumnya jamur yang ditemukan merupakan saprofit yang memiliki peran dalam mendegradasikan sisakayu yang telah mati dan beberapa termasuk parasit.

Dari penelitian ini pula dapat diungkap bahwa jenis jamur kayu memiliki kemampuan adaptasi yang lebih baik dikarenakan memiliki tingkat toleransi yang lebih baik terhadap intensitas cahaya Khususnya jamur Ganodremasp, Postia Sitipticus dan Nigroporusvinosus. Jamur kayu juga memiliki kemampuan adaptasi yang tinggi terhadap perubahan musim karena jamur jenis ini tidak tergantung pada tanah seperti tingkat kelembapan tanah atau ketersediaan air, serta nutrisi dalam tanah yang lebih mudah hilang karena berbagai faktor misalnya iklim dimana menurut Hikmatullah (2009) curah hujan yang tinggi berpengaruh terhadap proses pencucian basa-basa, sehingga $\mathrm{pH}$ tanah cenderung lebih asam, sementara itu pernyataan Gardner et al.(1991) dalam Khayati (2016) berpendapat bahwa kebanyakan nutrient tersedia dalam $\mathrm{pH}$ antara 6-7 untuk pertumbuhan jamur. Akan tetapi nutrisi dan air yang dibutuhkan jenis jamur kayu diperoleh dari sisa tanaman yang telah mati maupun secara parasit yang tentunya banyak mengandung air dan nutrisi untuk pertumbuhannya. Sehingga jenis jamur kayu tentunya akan lebih tahan terhadap perubahan musim selama substratnya masih tersedia dan tidak tergantung dengan kandungan air dan nutrisi dalam tanah yang mudah berubah karena faktor lingkungan. 


\section{KESIMPULAN DAN SARAN}

\section{Kesimpulan}

Hasil penelitian dapat diperoleh Jenis jamur makroskopis yang ditemukan di kawasan hutan lindung Kaleakan, terdiri atas 33 Spesies yang semuanya merupakan Divisi Basidiomycota yang terdiri atas 3 Kelas, 8 Ordo, 22 Famili dan 28 Genus. Kelompok jamur dari Ordo Polyporales dan family Poliporaceae merupakan kelompok jamur yang paling banyak ditemukan jenisnya karena memiliki kemampuan adaptasi yang tinggi. Berdasarkan tutupan lahan, pada daerah bekas kebakaran yang memiliki tingkat intensitas cahaya tinggi, ditemukan 3 jenis jamur, yaitu jamur Ganoderma applatum, Postiastipticus dan Nigroporusvinosus. Berdasarkan substratnya pada kayu lapuk ditemukan 19 jenis (53\%), serasah/tanah 13 jenis (36\%) dan pada kayu hidup 4 jenis (11\%). Hal itu mengindikasikan bahwa kebanyakan jamur yang hidup di kawasan hutan lindung Kaleakan Kecamatan Nanggala Toraja Utara adalah jenis jamur kayu (wood fungy) yang umumnya berperan sebagai Sabrofit, pelapuk kayu/dekomposer.

\section{Saran}

Penulis berharap agar penelitian ini dapat dijadikan sebagai sumber informasi mengenai Jamur khususnya jamur makroskopis, selain itu penulis juga menyadari betul berbagai kekurangan dalam penelitian ini karena berbagai faktor, seperti keterbatasan sumberdaya, biaya, waktu dan pendukung lainnya. Selain itu disarankan juga untuk penelitian selanjutnya agar melakukan penelitian di musim yang berbeda agar memberikan akurasi terhadap hasil penelitian yang lebih baik

\section{DAFTAR RUJUKAN}

Annissa, Hanna Artuti Ekamawanti, Wahdina. 2017. Keanekaragaman Jenis Jamur Makroskopis di Arboretum Sylva Universitas Tanjungpura.JurnalHutan Lestari (Online) Vol 5 No 4 (http://jurnal.untan.ac.id, Diakses 9 April 2019).

Anonim $_{1.2016}$. Buku Putih Sanitasi (BPS) Kelompok Kerja Sanitasi Kabupaten Toraja Utara (Online), (https://ppsp.nawasis.info, Diakses 2 April 2019).

Anonim2. 2018. Rencana Pengelolaan Hutan Jangka Panjang KPHL Unit VII Pada UPT KPH Saddang II KabupatenToraja Utara Provinsi Sulawesi Selatan Periode 2019-2028: DinasKehutananProvinsi Sulawesi Selatan.

Anonim4. 2015. Fungi Identification( online) (https://www.first-nature.com, Diakses 1 Mei 2019)

Chakraborty et al. 2017.A new species of Xerocomus (Boletaceae) from India.Mycosphere (online) Vol 8 No 1 (http://www.mycosphere.org, diakses 5 Juni 2019)

Eppo. 2008.EPPO Global Database. (https://gd.eppo.int/taxon/diakes 2 Juni 2019)

Emberger Gary. 2008. Fungi Growing on Wood. Messiah College (online) (https://www.messiah.edu/Oakes/fungi_on_wood, Diakses 5Mei 2019)

GandjarIndrawati, Wellyzar, Oetari,.2018. Mikologi Dasar dan Terapan. Jakarta: Yayasan Pustaka Obor.

Handayanto dan Hairiah. 2009. Biologi Tanah LandasanPengelolaan Tanah Sehat. Yogyakarta: Pustaka Adipura. 
Hadijah. 2009. Kelembagaan dan Kebijakan PengelolaanHutandalamOtonomi Daerah di Kabupaten Tana Toraja .Fakultas Kehutanan, Universitas Hasanuddin (Online), (https://kelembagaandas.wordpress.com, Diakses 2 April 2019).

Hikmatullah, Sukarman. 2007. Evaluasi Sifat-Sifat Tanah pada Landform Aluvial di Tiga Lokasi di KabupatenDonggala, Sulawesi Tengah.Jurnal Tanah dan Iklim (online) Vol 1 No 25 (https://media.neliti.com, Diakses 8 juni 2019).

Himawan.2017. Uniknya Iklim di Sulawesi Selatan.(http://news.rakyatku.com//, Diakses 8 Juni 2019)

Iswanto. 2009. Identifikasi Jamur Perusak Kayu. KaryaTulis. Medan: Universitas Sumatera Utara.

Kuo Michael 2010. Studyng mushroom.(https://www.mushroomexpert.com , Diakses 28 April 2019)

Khayati, Hadi Warsito.2016. Keanekaragaman Jamur Kelas Basidiomycetes di

Kawasan Lindung KPHP Sorong Selatan.Prosiding Symbion(Symposium on

Biology Education),(Online). Vol 1 No 1 (http://symbion.pbio.uad.ac.id , Diakses 1 Juni 2019).

Liswidyawati. 2012. BudidayaJamur. Jakarta: Agro Media Pustaka

Lestari, YuliFebrianti. 2018. Identifikasi Makrofungi Ordo Polyporalesdi Kecamatan Purwodadi Kabupaten Musi Rawas. Jurnal IJOBB, (Online) Volume 2 No 1 (https://ejurnal.esaunggul.ac.id, Diakses 8 Juni 2019)

Matheny. 2009. A Phylogenetic Classification of the Inocybaceae.McIlvainea (online).Vol 18 No 1. (https://www.namyco.org/docs/3_Matheny.pdf, diakses 5 Juni 2019)

RahmaKairini. 2018. Karakteristik Jamur Makroskopis di Perkebunan Kelapa Sawit Kecamatan Meureubo Aceh Barat Sebagai Materi Pendukung Pembelajaran Kingdom Fungi Di Sma Negeri 1 Meureubo.Skripsi.Tidak diterbitkan. Banda Aceh: FakultasTarbiyah dan Keguruan Universitas Islam Negeri Ar-Raniry Darussalam.

RedaksiPalopo Pos. 2018.Luwu Raya Masuk Non Zona Musim.(https://palopopos.fajar.co.id/2018/05/22/luwu-raya-masuk-non-zonamusim/, diakses 8 Juni 2019)

Suriawiria, U. 2006. Budidaya Jamur Tiram. Yogyakarta: Kanisius.

Subardi, Nuryani, Pramono. 2009. Biologi Untuk Kelas X SMA dan MA. Jakarta: Pusat PerbukuanDepartemen Pendidikan Nasional.

Susan dan Retnowati. 2018. Catatan Beberapa Jamur Makro dari Pulau Enggano: Diversitas Dan Potensinya. Jurnal Ilmu-ilmuHayati. (Online) Vol 16 No 3 (http://e-journal.biologi.lipi.go.id, Diakses 2 Juni 2019).

Sri Sumarni, dkk. 2017. Identifikasi Jenis Jamur Makroskopis Di Kawasan Hutan Lindung Bukit Rentap Desa Ensaid Panjang Kecamatan Kelam Permai Kabupaten Sintang.Fakultas Pertanian Universitas Kapuas Sintang.(Online) Vol 1 No 1 (http://jurnal.unka.ac.id, Diakses 1 Juni 2019).

Tambaru, dkk. 2016. Jenis-Jenis Jamur Basidiomycetes Familia Polyporaceae diHutan Pendidikan Universitas Hasanuddin Bengo-Bengo Kecamatan Cenrana Kabupaten Maros. Jurnal Biologi Makassar (Bioma),(Online) Vol 1 No 1 (http://journal.unhas.ac.id, Diakses 28 Mei 2019).

Undang-Undang Republik Indonesia Nomor 41 Tahun 1999 Tentang Kehutanan. 